http://jmscr.igmpublication.org/home/

ISSN (e)-2347-176x ISSN (p) 2455-0450

crossref DOI: https://dx.doi.org/10.18535/jmscr/v8i5.79

Journal Of Medical Science And Clinical Research

IGM Publication

An Official Publication of IGM Publication

\title{
Comparative study of effectiveness of Ormeloxifene and Medroxy Progesterone Acetate in the management of Dysfunctional Uterine Bleeding
}

\author{
Authors \\ Dr S. Manjula1, MD., Dr G. Ambujam², MS., Dr Alla Satyanarayana Reddy ${ }^{3 *}$, MD. \\ ${ }^{1}$ Associate Professor in Obstetrics \& Gynaecology \\ ${ }^{2}$ Professor in General Surgery \\ ${ }^{3}$ Professor in Obstetrics \& Gynaecology \\ Vinayaka Mission`s Research Foundation (DU), Karaikal, Pondicherry, India \\ *Corresponding Author \\ Dr Alla Satyanarayana Reddy
}

Professor in OBG, Vinayaka Mission`s Medical College and Hospital, Karaikal, Pondicherry, India. 609609

\begin{abstract}
Abnormal uterine bleeding without any systemic or local structural causes was earlier termed dysfunctional uterine bleeding. It is nearly equivalent to COE of the new FIGO classification of AUB. Ormeloxifene is a non steroidal, nonhormonal, selective receptor modulator inhibitor, widely used as an oral contraceptive. In the past decade, Ormeloxifene was well established in the control of menorrhagia. This is a prospective, randomised, comparative study of the efficacy of Ormeloxifene and Medroxy Progesterone Acetate (MPA) in the control of bleeding in DUB. A group of sixty women, had Ormeloxifene $60 \mathrm{mg}$ twice a week for 12 weeks and once a week for a further 12 weeks. Another group of sixty women, had MPA 20 mg a day cyclically for 21/28 days for six months. Hb level, endometrial thickness and PBAC score are the parameters analysed. In both groups, there is a significant improvement in Hb level. In control of bleeding, the action of Ormeloxifene is seen in a month and the benefit continued throughout the treatment. With MPA, the control of bleeding is not satisfactory in the first cycle, but from second cycle, there is satisfactory control of bleeding, slightly less than that of Ormeloxifene. During the course of treatment, 1/4th of women in Ormeloxifene group and 1/8 th of women MPA group became amenorrhic.
\end{abstract}

Keywords: AUB; DUB; Menorrhagia; Ormeloxifene; Medroxy progesterone acetate.

\section{Introduction}

Abnormal uterine bleeding (AUB) is any bleeding from the uterus which is not normal cyclical menstruation. It is a symptom, not a diagnosis. Excessive bleeding in amount or duration is a cause of worry to the patient and the clinician. Dysfunctional uterine bleeding is an earlier diagnostic term used when there is no systemic or locally definable structural cause of AUB. It is a diagnosis of exclusion. Women who fit this description, generally have one or a combination of coagulopathy, disorder of ovulation and primary endometrial disorder - the COE of PALM COEIN of FIGO ${ }^{(1)}$. DUB is a common debilitating problem accounting for $20 \%$ of all gynaecological consultations ${ }^{(2)}$.

The treatment modalities for DUB are A). Surgical- therapeutic D\&C, Hysterectomy ;B). Medical -NSAIDs, anti fibrinolytics, 
progesterone, levonorgestrel intra uterine system, combined oral contraceptives, danazol, GnRH. The choice of treatment depends on the age of the patient, fertility status and the severity of bleeding. The ideal drug should be, easy to use, cost effective, patient friendly, long lasting result if not permanent result, without much side effects. None of the drugs used have all these beneficial qualities,

Ormeloxifene popularly called Centchroman is a Selective Estrogen Receptor Modulator (SERM). It is estrogenic in some structures like bones and anti estrogenic in other parts like uterus and breast $^{(3)}$. It is widely used as anon hormonal, non steroidal oral contraceptive under the trade namesSaheli, Centron, Sevista. It causes an asynchrony between ovulation and development of endometrium $^{(4)}$. In the past decade, it has established itself as a safe and effective drug in the management of menorrhagia ${ }^{(5)}$.

Cyclical use of progesterones like nor ethisterone and Medroxy Progesterone Acetate (MPA)is a safe and effective therapy for regularisation of cycles and for the control of menorrhagia ${ }^{(6)}$. The disadvantage is, it has to be used cyclically, 21/28 or 10-12/28 days regularly. In women in the 4 th decade of life, its effect on glucose metabolism has to be looked into. Centchroman is used twice a week for three months, later once a week, which is a patient friendly dose.

In this study, an attempt is made to establish the efficacy of centchroman and MPA--A). in the management of menorrhagia in DUB, and B).to compare the efficacy of the two drugs objectively and subjectively.

\section{Aim and Objective}

To compare the efficacy of Centchroman and Medroxy Progesterone Acetate in control of bleeding in women with DUB

\section{Material and Methods}

The study was conducted by the authors in their parent institution and in their private consultation chambers in a city in Pondicherry state during the period January 2014 to June 2019. Women who completed their child bearing function, sterilised or not; having menorrhagia for some months are the subjects of the study. DUB was confirmed by exclusion of all other causes of AUB. Women $>45$ years of age; history of cancer of uterus or breast in the family; women who underwent breast or upper genital tract operations earlier; who had a hormonal treatment in the past three months; endometrial thickness more than $15 \mathrm{~mm}$; having a liver disease, thromboembolic disease, migraineare excluded from the study.

Women who are willing to continue medical treatment for DUB for six months were only enrolled for the study. Discontinuation of the treatment and switching over to another mode of treatment, if necessary, in these six months was discussed with the patient. Ethical committee clearance and informed consent of the patient was obtained. Women with DUB were examined clinically, necessary investigations and premenstrual ultrasonography for endometrial thickness was done. Endometrial sampling was done by Pipelle in all women. Pictorial Blood loss Assessment Chart (PBAC) was done by the patient in the earlier menses before drafting into the treatment and also in the cycle of initiation of the treatment - there by having a treatment free observational period of a month.

The women were allotted randomly to two groups — Group A, having Centchroman $60 \mathrm{mg}$ twice a week on fixed days Sunday and Wednesday for 12 weeks (though centchroman can be started on any day of cycle, we started in the menstrual phase of first treatment cycle for convenience and comparison) and once a week for the next 12 weeks. Group B having Medroxy Progesterone Acetate $20 \mathrm{mg}$ daily from 5 th day to 25 th day of every cycle for six menstrual cycles. The women were followed up every month for three months and later at the end of six months. PBAC was maintained by the patient. Endometrial thickness was done by TVS premenstrually. At every visit, weight gain, Hb level, FBS, patient`s satisfaction 
about the treatment and her subjective assessment of control of bleeding was enquired.

\section{Results}

A total of 76 women were drafted into group A, to get 60 women who completed the course for six months as per the protocol. In group B, 84 women has to be recruited to get 60 women to complete the course. In group A, one woman opted for hysterectomy on own, five women lost for follow up in the initial three months. Seven women lost for follow up at 24 weeks, three women underwent hysterectomy--two patient initiated and one doctor suggested. In group B eight women discontinued treatment in the initial 12 weeks, (understandably when the bleeding control was not to their satisfaction), one underwent therapeutic D\&C for control of bleeding; at 24 weeks, ten women lost for follow up; five women underwent hysterectomy--two indicated and three patient initiated. 84 women started the treatment and 60 women completed the treatment as per protocol.

\section{Table 1}

\begin{tabular}{|l|c|c|}
\hline Parameter & Group A: N=60 & Group B: N=60 \\
\hline Initiation of treatment & 76 & 84 \\
\hline Lost for follow up or discontinued treatment in 12 weeks & 5 & 8 \\
\hline Switched over to other treatment in 12 weeks & 1 & 1 \\
\hline At 12 weeks, patients on treatment & 70 & 75 \\
\hline Lost for follow up in 12-24 weeks & 7 & 10 \\
\hline Switched over to another treatment in 12-24 weeks & 3 & 5 \\
\hline Medically indicated hysterectomy & 1 & 3 \\
\hline Patient opted for hysterectomy & 2 & 3 \\
\hline At 24 weeks & 60 & 60 \\
\hline Median age of the women, in years & 30.6 & 31.0 \\
Range in years & $24-43$ & $26-45$ \\
\hline
\end{tabular}

Table 2

\begin{tabular}{|l|c|c|c|c|c|}
\hline Parameter At 0 weeks & At 4 weeks & At 8 weeks & At 12 weeks & At 24 weeks \\
\hline Haemoglobin & $7.4,7.5$ & & & $9.2,8.6$ & $10.3,10.2$ \\
\hline Dysmenorrhoea & $43 \%, 45 \%$ & & & $9 \%, 10 \%$ & $8 \%, 14 \%$ \\
\hline ET in mm & $11.3,11.0$ & & & $5.7,5.4$ & $5.6,5.9$ \\
Range & $7.1-15,6.9-14$ & & & $4.3-10,4.6-11$ & $4.4-12,4.1-13$ \\
\hline Menorrhagia control in \% & & 79,46 & 84,78 & 82,80 & 88,76 \\
of women & & & & 86,92 & 92,95 \\
\hline Mean PBAC score & 276,255 & 109,129 & 98,110 & $76-142$, & $80-156$, \\
Range & $125-354$, & $74-153$, & $70-124$, & $71-136$ & $76-148$ \\
\hline Subjective evaluation of & $113-320$ & $86-197$ & $81-155$ & ++++++ &,++++ \\
amount of bleeding & ++++++ &,++++++ &,++++ & & + \\
\hline Satisfied about treatment & & & & 70,58 & 68,49 \\
\hline
\end{tabular}

Legend: Values in red colour: Group A with Centchroman. Values in black colour: Group b with MPA

The age of the women in group A, median 30.6 years with a range of 24-43 years; where as in group $\mathrm{B}$, the median age is 31.0 , with a range of 26-45 years.

The average haemoglobin level in group $\mathrm{A}$ women at initiation of treatment was $7.4 \mathrm{Gms} \%$, improved to 9.2 grams at 12 weeks and 10.3 at 24 weeks. The comparative figures for group B were 7.5, 8.6,10.2 respectively

In group A, $45 \%$ of women had some dysmenorrhoea at initiation of treatment, and after treatment less than $10 \%$ had dysmenorrhoea; compared with $43 \%$ at initiation, $8 \%$ at 3 months and $14 \%$ at 6 months in group B.

Endometrial thickness was a mean of $11.3 \mathrm{~mm}$, with a range of 7.1-15 in group $A$ at initiation of treatment. The mean endometrial thickness was 5.7, $5.4 \mathrm{~mm}$ at 12 weeks and 24 weeks. In group 
$\mathrm{B}$, the mean endometrial thickness was 11.0, 5.6, $5.9 \mathrm{~mm}$ at initiation, 12 weeks and 24 weeks respectively

The mean PBAC scores at initiation of treatment were 276 with a range of 125-354 in group A, and the corresponding figures were $225,113-320$ for group B.

After one month of treatment, $79 \%$ of women in group A had control of menorrhoea; in group Bonly $46 \%$ had control of menorrhagia. From two months of treatment, the percentage of women who had control of menorrhagia in group A were $84,82,88$ at 2,3,6 months respectively; the corresponding values for group B were, 78, 80, 76.

The mean PBAC scores were 109, 98, 86, 92 at 4, $8,12,24$ weeks of treatment in group A ; compared with $129,110,92,95$ at 4,8,12,24 weeks for group B.

At every visit, the women were asked to assess their bleeding subjectively as per their perception in a scale of 1-5. The median rating of bleeding were 5,4,2,2,2 at $0,1,2,3,6$ months in group A; the corresponding ratings in group B were 5,4,2,2,2.

The general assessment of the women, about the treatment-79, 70, $68 \%$ of women were satisfied with the treatment at 1,2,6 months of treatment in group A. The corresponding figures for group B were $43,58,49 \%$.

\section{Discussion}

The ultimate aim of the treatment of DUB is control of bleeding and the resultant increase in the haemoglobin level. Both, Centchroman and MPA are useful in the management of DUB.

Ravibabu Komaram et al. noted that the mean PBAC score was reduced by $58 \%$ at the end of six months of usage of centchroman ${ }^{(9)}$

Hari Om Singh et al. reported that there was a reduction of PBAC score from 317 to 105 after six months of usage of centchroman. In this series of patients, at the end of the treatment, $15 \%$ of the patients are having heavy or very heavy bleeding $^{(10)}$.
Jacob et al. reported a $74.7 \%$ reduction in PBAC score with centchroman and $55.9 \%$ reduction with nor ethisterone ${ }^{(7)}$.

Jimit Kumar Jamana das et al compared centchroman with combined oral contraceptives. In their series of cases after six months of treatment, the PBAC score was reduced by $57 \%$ with centchroman and $38 \%$ with $\mathrm{COC}^{(8)}$.

Kripalani a et al. in their trend setting study using centchroman, reported that $43 \%$ of women had amenorrhoea; $17 \%$ had no response; the mean PBAC score was less by $98 \%$ after six months of treatment $^{(5)}$.

Zeepee Godha et al. compared the efficacy of centchroman and MPA in a large series of patients more than 200 in each group. They reported a reduction in median PBAC score by $79.4 \%$ in centchroman group and $75 \%$ in MPA group ${ }^{(11)}$.

In the present study, after a month of usage of centchroman, the median PBAC decreased from 276 to 109 and with MPA from 255 to 129- a reduction of $62.5 \%$ vs $49 \%$. While taking into consideration 100 PBAC as the limit of menorrhagia, $79 \%$ of women had control of bleeding with centchroman, compared with only $46 \%$ in MPA group. But after another cycle of treatment, the MPA group of women had a result almost equal to that of centchroman group of women--78\% vs $84 \%$. At completion of six months of usage of both the drugs, the median PBAC came down from 276 to 92 in with centchroman and 255 to 95 with MPA; the overall control of menorrhagia being $88 \%$ with centchroman and $76 \%$ with MPA. 14 women in centchroman group $(23.3 \%)$ and 8 women from MPA group (13.3\%) became amenorrhoic. The mean Endometrial thickness was $11.3 \mathrm{~mm}$ initially and $5.6 \mathrm{~mm}$ at completion of treatment with centchroman; and the figures with MPA were 11.0 $\mathrm{mm}$ and $5.9 \mathrm{~mm}$.

The results of our study are similar to that quoted by Zeepee Godha et al. In a clinical scenario, it is not the objective PBAC, but the subjective bleeding observed by the patient is important to her. Centchroman patients rated their bleeding as 
+++++ at start of treatment and from the first month onwards, they rated the bleeding as ++ till the completion of six months of treatment; whereas women on MPA rated their bleeding as +++++ initially, ++++ at one cycle of treatment, and ++ from two months onwards. The $\mathrm{Hb} \%$ rose from $7.4 \mathrm{gms} \%$ to $10.3 \mathrm{gms} \%$ in group A and from $7.5 \mathrm{gms} \%$ to $10.2 \mathrm{gms} \%$ in group B. Some amount of dysmenorrhoea was complained by 40$45 \%$ of women at the start of treatment; and only by $10-15 \%$ of women at the completion of treatment. After discontinuation of treatment, the recurrence of the problem was seen in 8 women with centchroman and in $13 \%$ with MPA treatment.

Overall, $68 \%$ of women in centchroman group and only $49 \%$ of women in MPA group are satisfied with their treatment, even though the results are almost same. The reason may be their expectation of a cure of the disease than the management of the problem. Daily usage of MPA. vs once or twice a week usage of centchroman might have weighed in the rating of success from the patient's point of view.

\section{Conclusions}

Centchroman is an effective medical management of DUB. More than 3/4ths of women had control of bleeding and $1 / 4$ th of women became amenorrhic with treatment. Medroxy Progesterone Acetate is also effective in the management of DUB, but slightly lesser than Centchroman. Both of these drugs are suggested as treatment for DUB, thereby avoiding surgery.

\section{Conflict of interest: Nil}

\section{References}

1. Munro MG, Critchley HO, Broder MS, et al. FIGO classification system (PALMCOEIN) for causes of abnormal uterine bleeding in non gravid women of reproductive age. FIGO Working Group on Menstrual Disorders. Int J Gynaecol Obstet. 2011;113:3-13.
2. Awwad JT, Toth TL, Schiff I. Abnormal uterine bleeding in the perimenopause. Int J Fertil. 1993;38:261

3. Kumar GR, Rituraj K, Hemant BK, Singh MM. The in-vitro anti-cancer breast activity of ormeloxifene is mediated via the induction of apoptosis and autophagy. 37th Annual Conference of the Endocrine Society of India.30 Nov-2 Dec, 2007. Abstract p35

4. Singh MM. "Centchroman, a selective estrogen receptor modulator, as a contraceptive and for the management of hormone-related clinical disorders". Medicinal Research Reviews. 2001; 21 (4): 302-47

5. Kriplani A, Kulshrestha V, Agarwal N. Efficacy and safety of ormeloxifene in management of menorrhagia: a pilot study. J Obstet Gynaecol Res. 2009;35:746-52.

6. Studd J. Progress in obstetrics and gynecology. In: Current minimal access techniques for dysfunctional uterine bleeding. Churchill Living Stone, 2003; 15: 259-272.

7. Jacob KJ, Mini, Deepak AV. A comparative study on the effectiveness of ormeloxifene versus norethisterone in the management of perimenopausal dysfunctional uterine bleeding. IAIM, 2015; 2(7): 87-92.

8. Chhatrala JJ et al. Int J Reprod Contracept Obstet Gynecol. 2015 Apr;4(2):366-369

9. Ravibabu Komaram et al., A Study of Efficacy of Ormeloxifene in the Pharmacological Management of Dysfunctional Uterine Bleeding Journal of Clinical and Diagnostic Research. 2013 Nov, Vol-7(11): 2534-2536

10. Singh HO, Singh A, Dhole TN, Nain S (2015) Effect of Ormeloxifene for Management of Dysfunctional Uterine Bleeding. Biochem Physiol 4: 174. doi: 10.4172/2168-9652.1000174 
11. Godha et al. The Journal of Obstetrics and Gynecology of India (September-October 2016) 66(S1):S395-S399. 